\title{
Downregulation of HIF-1 $\alpha$ inhibits the proliferation and invasion of non-small cell lung cancer NCI-H157 cells
}

\author{
JIALIN QIAN, HAO BAI, ZHIQIANG GAO, YU DONG, JUN PEI, MEILI MA and BAOHUI HAN
}

\begin{abstract}
Department of Respiratory Medicine, Shanghai Chest Hospital, Shanghai Jiao Tong University, Shanghai 200030, P.R. China
\end{abstract}
Received January 27, 2015; Accepted December 2, 2015

DOI: $10.3892 / \mathrm{ol} .2016 .4150$

\begin{abstract}
Lung cancer, specifically non-small cell lung cancer (NSCLC), is the leading cause of cancer-associated mortality in the world. In previous years, almost no significant advancements have been made towards the molecular characterization of NSCLC, which highlights the requirement for novel target genes. Hypoxia inducible factor- $1 \alpha(\mathrm{HIF}-1 \alpha)$ is known to be essential in tumorigenesis, as it regulates the expression of numerous factors that are involved in angiogenesis, cellular proliferation and apoptosis. However, no direct association between HIF-1 $\alpha$ and NSCLC treatment has previously been established. The aim of the present study was to characterize the effect of HIF-1 $\alpha$ on NSCLC and to explore the possible mechanism. Additionally, HIF-1 $\alpha$ small interfering (si)RNA and diamminedichloroplatinum (DDP) were used in combination to explore the combined effects on NSCLC cells. Lung carcinoma NCI-H157 cells were treated with HIF-1 $\alpha$ small interfering (si)RNA, $5 \mu \mathrm{g} / \mathrm{ml}$ DDP or a combination of the two, and the proliferation, apoptosis and invasion ability of the cells were detected using a cell counting kit- 8 assay, Annexin V/propidium iodide staining and a Transwell assay, respectively. In addition, the protein levels of caspase-3/9, anti-apoptotic protein B-cell lymphoma-2 (Bcl-2), vascular endothelial growth factor (VEGF), pigment epithelium-derived factor (PEDF), phosphoinositide 3-kinase (PI3K), phosphorylated (p-)PI3K, protein kinase B (AKT), p-AKT, extracellular signal-regulated kinase (ERK) and p-ERK were detected using western blot analysis. Similar to DPP treatment, HIF- $1 \alpha$ siRNA treatment may reduce cell proliferation and the invasiveness of tumor cells while promoting apoptosis. Additionally, HIF-1 $\alpha$ siRNA may increase the levels of the apoptotic proteins caspases 3 and 9 and inhibit the expression of Bcl-2. These anti-tumor effects may be acting through the VEGF/PEDF, PI3K/AKT and Raf/mitogen-activated protein kinase kinase/ERK signaling pathways. The effects of HIF-1 $\alpha$ siRNA may be strengthened
\end{abstract}

Correspondence to: Dr Baohui Han, Department of Respiratory Medicine, Shanghai Chest Hospital, Shanghai Jiao Tong University, 241 West Huaihai Road, Shanghai 200030, P.R. China

E-mail: hanbaohui@126.com

Key words: downregulation, inhibit, non-small cell lung cancer by DDP. The present data indicated that HIF-1 $\alpha$ siRNA is important in the inhibition of NSCLC cells. Additionally, the effects of HIF-1 $\alpha$ siRNA may be strengthened by DDP, which suggests that HIF-1 $\alpha$ siRNA may be combined with DDP for the treatment of tumors.

\section{Introduction}

Lung cancer is extremely harmful to human health and has the highest worldwide incidence of all malignant tumors (1). Overall, $~ 80 \%$ of lung cancers are classified as non-small cell lung cancer (NSCLC) (2), which is the leading cause of cancer-associated mortality in the industrialized world (3). Despite the significant progress made in the treatment of early-stage NSCLC, the survival rate of the advanced stage NSCLC remains extremely low (4). Although several therapeutic targets have been developed previously, there continues to be no effective therapeutic target for the augmentation of the cure rate (5). Therefore, the development of novel and effective therapeutic targets to successfully treat NSCLC is urgently required (6,7). Additionally, novel methods to simultaneously inhibit multiple therapeutic targets, including well-known targets and innovative therapeutic targets, have been developed $(8,9)$.

Hypoxia-inducible factor- $1 \alpha(\mathrm{HIF}-1 \alpha)$ is widespread in mammalian and human cells (10) under hypoxic conditions (11). HIF- $1 \alpha$ is a transcription factor indicated in extracts of a hypoxia-induced cell nucleus $(12,13)$. HIF-1 $\alpha$ may promote the transcription of hypoxia adaptation genes, including vascular endothelial growth factor (VEGF) genes, by binding with the promoter or enhancer region of these genes (10,14-16). Overexpression of the HIF-1 $\alpha$ protein has been detected in a variety of malignant tumors and precancerous lesions $(12,17)$, but has never been indicated in normal tissues and benign lesions (18). Certain studies have demonstrated that the overexpression of HIF-1 $\alpha$ is closely associated with tumor growth (19), angiogenesis (20), invasion and metastasis (21-23), but the molecular mechanisms and signaling pathways involved remain unclear. Numerous studies have confirmed that HIF-1 $\alpha$ is important in hypoxia-mediated apoptosis and proliferation in testicular tumor cells $(14,24)$. Hypoxic environments widely exist in NSCLC $(25,26)$, which indicates the association between HIF- $1 \alpha$ and NSCLC $(13,27)$. However, whether HIF-1 $\alpha$ is associated with the proliferation and apoptosis of NSCLC cells remains unclear. 
In the present study, the effects of HIF-1 $\alpha$ knockdown on the proliferation and invasion of NSCLC cells were investigated, and the specific mechanisms and signaling pathways were explored. The present study may provide support for the drug development and clinical treatment of NSCLC.

\section{Materials and methods}

Reagents. The rabbit polyclonal anti-human caspase-3 (catalog no., Ab4051; dilution, 1:400), rabbit polyclonal anti-human caspase-9 (catalog no., Ab2014; dilution, 1:1,000), rabbit polyclonal anti-human VEGF (catalog no., Ab46154; dilution, 1:1,000), mouse monoclonal anti-human pigment epithelium-derived factor (PEDF; catalog no., Ab115489; dilution, 1:1,000) and mouse monoclonal anti-human phosphoinositide 3-kinase (PI3K; catalog no., Ab86714; dilution, 1:1,000) antibodies were obtained from Abcam (Cambridge, MA, USA). The rabbit polyclonal anti-human protein kinase B (AKT; catalog no., 9272S; dilution, 1:1,000), rabbit polyclonal anti-human extracellular signal-regulated kinase (ERK; catalog no., 9102; dilution, 1:1,000), rabbit monoclonal anti-human phosphorylated (p-) ERK (catalog no., 4370S; dilution, 1:1,000), rabbit polyclonal anti-human p-PI3K (catalog no., 4228; dilution, 1:1,000) and rabbit monoclonal anti-human p-AKT (catalog no., 4058S; dilution, 1:1,000) and rabbit monoclonal anti-human glyceraldehyde 3-phosphate dehydrogenase (GAPDH; catalog no., 5471; dilution, 1:1,500) antibodies were obtained from Cell Signaling Technology, Inc. (Danvers, MA, USA). The rabbit polyclonal anti-human B-cell lymphoma-2 (Bcl-2; catalog no., Sc-492; dilution, 1:100) antibody was obtained from Santa Cruz Biotechnology Inc. (Dallas, TX, USA). Cell counting kit-8 (CCK-8) was obtained from Boster Biological Engineering Co., Ltd. (Wuhan, Hubei, China), Gibco Roswell Park Memorial Institute (RPMI)-1640 medium was obtained from Thermo Fisher Scientific (Waltham, MA, USA), HyClone fetal bovine serum (FBS) was obtained from GE Healthcare Life Sciences (Logan, UT, USA) and glutamine was purchased from Sigma-Aldrich (St. Louis, MO, USA). The TIANScript reverse transcription (RT) and RNAsimple Total RNA kits were obtained from Tiangen Biotech (Beijing) Co., Ltd. (Beijing, China), the Super Moloney murine leukemia virus (catalog no., PR6502) reverse transcriptase was obtained from BioTeke Corporation (Beijing, China), diamminedichloroplatinum (DDP) was obtained from JRDun Biotechnology Corp. (Shanghai, China), Invitrogen Lipofectamine 2000 (catalog no., 11668027) was purchased from Thermo Fisher Scientific and dimethyl sulfoxide was obtained from Sigma-Aldrich. The primers were synthesized by Sangon Biotech Co., Ltd. (Shanghai, China).

Cell culture. The lung carcinoma NCI-H157 cell line was purchased from the Cell Culture Center of the Shanghai Aiyan Biological Technology Co., Ltd. (Shanghai, China). The cells were grown in RPMI-1640 medium containing $10 \% \mathrm{FBS}$ and $2 \mathrm{mM}$ glutamine in a humidified incubator (Mco-15AC; Sanyo Electric Co. Ltd., Moriguchi, Osaka, Japan) at $37^{\circ} \mathrm{C}$ in $5 \% \mathrm{CO}_{2}$. The cells were split twice weekly and cells that were in the logarithmic growth phase were used for experiments.
Small interfering (si)RNA design and transfection. An irrelevant negative control (MOCK), non-specific siRNA and siRNA that target human HIF-1 $\alpha$, were designed and synthesized by Sangon Biotech (Shanghai, China). The cells were transfected with siRNA using Lipofectamine 2000, and the RNA was extracted $48 \mathrm{~h}$ subsequent to transfection.

RNA detection. RNA molecules were extracted using the RNAsimple Total RNA kit. Complementary DNA was synthesized using the TIANScript RT kit. Quantitative polymerase chain reaction (PCR) was performed to detect the RNA levels of HIF-1 $\alpha$. GAPDH was used an internal control. The primers used were as follows: HIF-1 $\alpha$ forward, 5'-TCGGCGAAGTAA AGAATC-3' and reverse, 5'-TTCCTCACACGCAAATAG-3'; and GAPDH forward, 5'-CACCCACTCCTCCACCTTTG-3' and reverse, 5'-CCACCACCCTGTTGCTGTAG-3'. The results were analyzed using Exicycler ${ }^{\mathrm{TM}} 96$ (Bioneer Corporation, Daejeon, South Korea). Each experiment was repeated 3 times.

CCK- 8 assay. NCI-H157 cell viability was measured using a CCK-8 assay with 2-(2-methoxy-4-nitrophenyl)-3-(4-nitrophenyl)-5-(2,4-disulfophenyl)-2H-tetrazolium salt. The NCI-H157 cells were seeded at a density of $5 \times 10^{3}$ cells per well into a 96-well microplate and incubated for $24 \mathrm{~h}$ at $37^{\circ} \mathrm{C}$. The peripheral wells of the microplate were filled with $200 \mu \mathrm{l}$ sterile phosphate-buffered saline (PBS). Subsequent to the addition of MOCK, 4 pmol HIF- $1 \alpha$ siRNA, $5 \mu \mathrm{g} / \mathrm{ml}$ DDP, $4 \mathrm{pmol} \mathrm{HIF-1} \alpha$ siRNA $+5 \mu \mathrm{g} / \mathrm{ml}$ DDP or MOCK $+5 \mu \mathrm{g} / \mathrm{ml}$ DDP, the cells were incubated for 0,24 and $48 \mathrm{~h}$. Subsequently, $10 \mu \mathrm{l}$ CCK-8 solution was added to each well and the wells were incubated for $1 \mathrm{~h}$ at $37^{\circ} \mathrm{C}$. Optical density (OD) was measured at a wavelength of $450 \mathrm{~nm}$ using a Multiskan Spectrum microplate reader (Thermo Fisher Scientific).

Flow cytometry assay. The NCI-H157 cells were inoculated into 6-well plates ( $5 \times 10^{5}$ cells/well). Subsequent to $24 \mathrm{~h}$ incubation, siRNA or $5 \mu \mathrm{g} / \mathrm{ml}$ DDP were added to the cells and the plates were incubated for another $24 \mathrm{~h}$. The flow cytometry assay was conducted according to the manufacturer's protocol for Annexin V-fluorescein isothiocyanate (FITC) Apoptosis Detection kit (Abcam, Cambridge, UK). Briefly, NCI-H157 cells were routinely digested, washed with $500 \mu \mathrm{l}$ PBS and centrifuged at $200 \times \mathrm{g}$ for $5 \mathrm{~min}$. The supernatant was aspirated and $100 \mu \mathrm{l}$ of Annexin V-FITC, at $1 \mathrm{~g} / \mathrm{ml}$ in 4-(2-hydroxyethyl)-1-piperazineethanesulfonic acid (HEPES; Beijing Solarbio Science \& Technology Co., Ltd., Beijing, China) buffer with $1.8 \mathrm{mM} \mathrm{CaC}_{12}$ (Beijing Solarbio Science \& Technology Co., Ltd.), was added to the NCI-H157 cells and incubated for 5-10 min at room temperature in the dark. Finally, $1 \mathrm{ml}$ of HEPES that contained $10 \mathrm{~g} / \mathrm{ml}$ propidium iodide was added. Samples were analyzed immediately using flow cytometry (BD Biosciences, Franklin Lakes, NJ, USA).

Detection of the cell invasive capacity using a Transwell assay. The Transwell chambers (Corning Inc., Corning, NY, USA) were first coated with Matrigel (dilution, 1:3; BD Biosciences) in Gibco serum-free RPMI-1640 for $2 \mathrm{~h}$ at $37^{\circ} \mathrm{C}$. The NCI-H157 cells were then digested with $0.25 \%$ trypsin (Beijing Solarbio Science \& Technology Co., Ltd.) to produce a single cell suspension. The suspension was diluted to a density of 
A

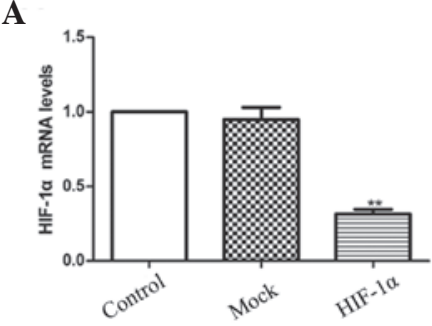

C

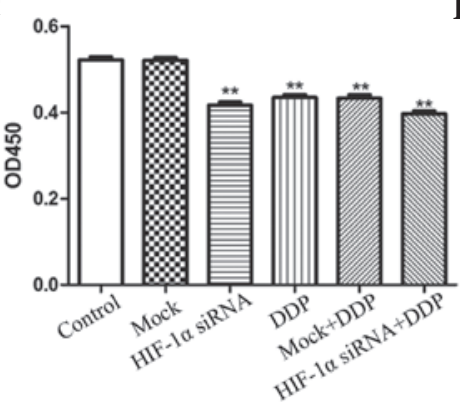

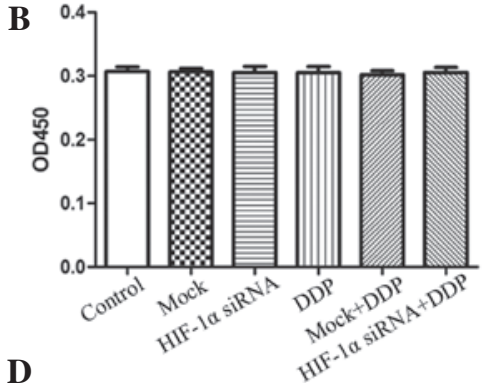

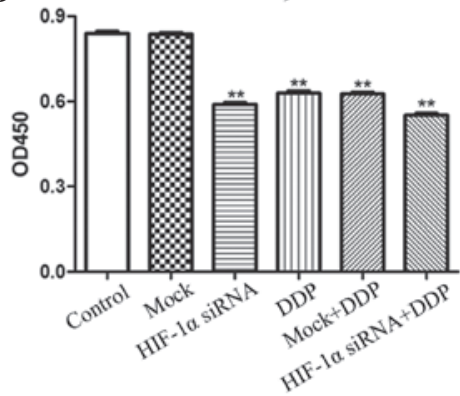

Figure 1. Proliferation of NCI-H157 cells detected using a CCK-8 assay. NCI-H157 cells were transfected with HIF-1 $\alpha$ siRNA or MOCK siRNA. (A) RNA levels of HIF-1 $\alpha$ was detected using a real-time polymerase chain reaction. Glyceraldehyde 3-phosphate dehydrogenase was used as an internal control. NCI-H157 cells were treated as described in the Materials and methods. Cell growth was detected using the CCK-8 assay at (B) 0 h, (C) 24 h and (D) 48 h. The data are expressed as the mean \pm standard deviation $(n=6)$. ${ }^{*} \mathrm{P}<0.05,{ }^{* *} \mathrm{P}<0.01$ vs. control. CCK-8, cell counting kit-8; HIF-1 $\alpha$, hypoxia-inducing factor-1 $\alpha$; siRNA, small interfering RNA; MOCK, irrelevant; DDP, diamminedichloroplatinum; OD, optical density.

$1 \times 10^{5}$ cells $/ \mathrm{ml}$ for use. A total of $800 \mu \mathrm{l}$ culture medium containing $20 \%$ FBS was added into the coated lower Transwell chambers, and $200 \mu 1$ of cell suspension was added into the upper Transwell chambers at a density of $5 \times 10^{4}$ cells/well. The plate was cultured for $24 \mathrm{~h}$. The Transwell chambers were removed and gently washed with PBS. The cells on the upper layer of the microporous membrane were removed using a cotton swab, fixed with paraformaldehyde (Beijing Solarbio Science \& Technology Co., Ltd.) for $20 \mathrm{~min}$ at room temperature, and stained with hematoxylin staining solution (Beijing Solarbio Science \& Technology Co., Ltd.) for $3 \mathrm{~min}$. The cells that migrated to the lower layer of the microporous membrane were counted in 5 fields under an inverted microscope (Olympus IX71/IX81; Olympus Corporation, Tokyo, Japan; magnification, $\mathrm{x} 200$ ) for each sample. The experiment was repeated three times.

Statistical analysis. All data are expressed as the mean \pm standard deviation (SD). Data were evaluated using the SPSS 16.0 statistical software package (SPSS, Inc., Chicago, IL, USA). Data were analyzed using one-way analysis of variance. $\mathrm{P}<0.05$ was considered to indicate a statistically significant difference.

\section{Results}

Knockdown of HIF-1 $\alpha$ by RNA interference decreased the proliferation of NCI-H157 cells. siRNA that targets human HIF-1 $\alpha$ was designed and transfected into NCI-H157 cells. HIF- $1 \alpha$ expression was inhibited by $\sim 70 \%$ by HIF- $1 \alpha$ siRNA ( $\mathrm{P}<0.01$; Fig. 1A), whereas HIF-1 $\alpha$ expression remained unaffected in the MOCK group. The type of HIF-1 $\alpha$ siRNA that inhibited HIF-1 $\alpha$ expression was selected for additional study.
The well-known anti-tumor drug DDP was used in the present study. A CCK-8 assay was performed in order to determine the effects of HIF- $1 \alpha$ siRNA administered with or without DDP on the cell proliferation capability of NCI-H157 cells. All groups possessed the same number of cells at $0 \mathrm{~h}$ (Fig. 1B). The growth capacity of NCI-H157 cells transfected with HIF-1 $\alpha$ siRNA or treated with DDP was significantly decreased at $24 \mathrm{~h}$ (Fig. 1C) and $48 \mathrm{~h}$ (Fig. 1D) compared with the Control and MOCK groups $(\mathrm{P}<0.01)$. More notably, the HIF-1 $\alpha$ siRNA+DPP group demonstrated a stronger inhibition of NCI-H157 cell proliferation compared with the NCI-H157 cells that were treated with DPP or HIF-1 $\alpha$ siRNA separately $(\mathrm{P}<0.05)$. The present results indicate that the downregulation of HIF-1 $\alpha$ may decrease the growth capacity of NCI-H157 cells, and that this effect may be augmented by DDP treatment.

HIF-1 $\alpha$ knockdown increased the apoptosis of NCI-H157 cells. To explore the involvement of HIF-1 $\alpha$ in cell apoptosis, Annexin V/propidium iodide (PI) staining was performed. As exhibited in Fig. 2, cell apoptosis was markedly increased in the HIF-1 $\alpha$ siRNA, DDP, MOCK+DDP and HIF-1 $\alpha$ siRNA+DDP groups, when compared with the expression in the control group $(\mathrm{P}<0.01)$. In addition, the cell apoptosis of the HIF-1 $\alpha$ siRNA+DDP group was greater than that of the HIF-1 $\alpha$ siRNA, DDP and MOCK+DDP groups $(\mathrm{P}<0.01)$. The present results indicate that the downregulation of HIF-1 $\alpha$ may increase the apoptosis of NCI-H157 cells, which may be strengthened by DDP treatment.

HIF-1 $\alpha$ knockdown decreased the invasion ability of NCI-H157 cells. Invasive ability is essential for the malignant biological behaviors of tumors. The present study also investigated whether HIF-1 $\alpha$ affected the invasive ability of 

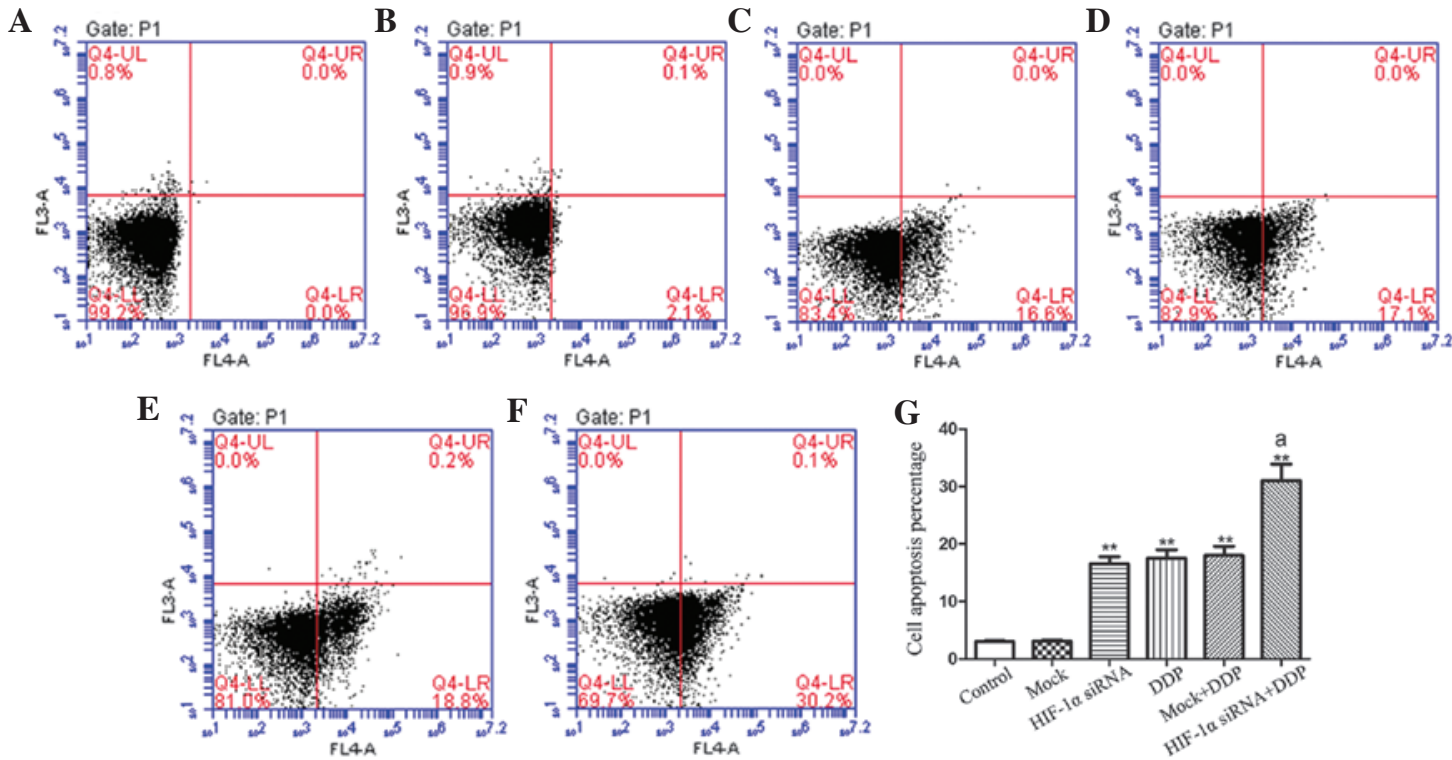

Figure 2. Apoptosis of NCI-H157 cells that were detected using Annexin V/propidium iodide staining in the (A) control (no treatment), (B) MOCK (controls transfected with one irrelevant siRNA), (C) HIF-1 $\alpha$ siRNA, (D) DDP, (E) MOCK with DDP and (F) HIF-1 $\alpha$ siRNA with DDP groups. (G) Statistical results of 3 experiments. The data are expressed as the mean \pm standard deviation $(n=6)$. Data were analyzed using one-way analysis of variance. ${ }^{*} \mathrm{P}<0.05$, ${ }^{* *} \mathrm{P}<0.01$ vs. control. ${ }^{\mathrm{P}} \mathrm{P}<0.01$ vs. HIF-1 $\alpha$ siRNA, DDP and MOCK+DDP. HIF-1 $\alpha$, hypoxia-inducing factor-1 $\alpha$; siRNA, small interfering RNA; MOCK, irrelevant; DDP, diamminedichloroplatinum.

A

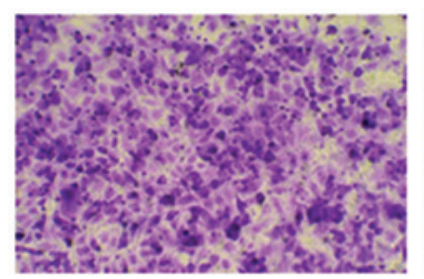

$\mathbf{E}$

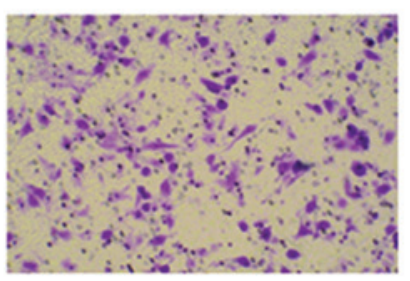

B

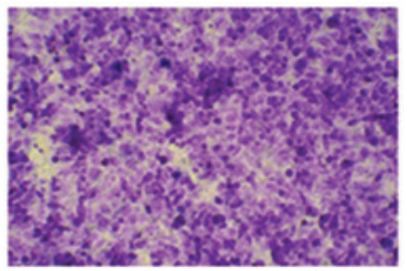

$\mathbf{F}$

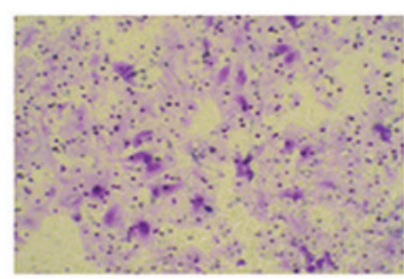

C

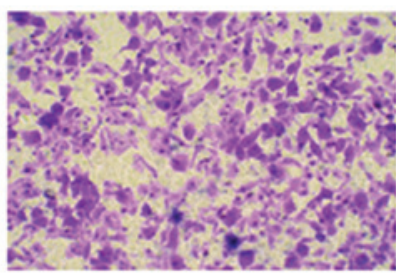

G

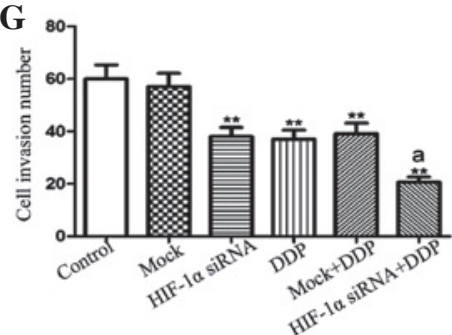

Figure 3. The invasive ability of NCI-H157 cells was detected using a Transwell assay. (A) Control group, no treatment. (B) MOCK group, controls transfected with irrelevant siRNA. (C) HIF-1 $\alpha$ siRNA group. (D) DDP group. (E) MOCK+DDP group. (F) HIF-1 $\alpha$ siRNA+DDP group. (G) Statistical results of 3 experiments. The data are expressed as the mean \pm standard deviation; $\mathrm{n}=6$. Data were analyzed using one-way analysis of variance. ${ }^{*} \mathrm{P}<0.05,{ }^{* * *} \mathrm{P}<0.01 \mathrm{vs}$. control. ${ }^{a} \mathrm{P}<0.01$ vs. HIF-1 $\alpha$ siRNA, DDP and MOCK+DDP. HIF-1 $\alpha$, hypoxia-inducing factor-1 $\alpha$; siRNA, small interfering RNA; DDP, diamminedichloroplatinum.

NCI-H157 cells. An in vitro invasion assay was performed in chambers that had the upper wells coated with Matrigel in order to mimic the extracellular matrix. In sharp contrast to the control cells, the HIF-1 $\alpha$ siRNA group, DDP group, Mock+DDP group and HIF-1 $\alpha$ siRNA+DDP groups demonstrated a dramatically reduced invasive ability $(\mathrm{P}<0.01$; Fig. 3$)$. The number of invasive cells in the HIF-1 $\alpha$ siRNA+DDP group was significantly increased compared to the number in the HIF- $1 \alpha$ siRNA or DDP groups $(\mathrm{P}<0.05, \mathrm{P}<0.01)$. The present results indicate that the downregulation of HIF-1 $\alpha$ may decrease the invasive ability of NCI-H157 cells, which may be potentiated by DDP treatment.
Associated proteins were regulated by the downregulation of $H I F-1 \alpha$. The results of the invasion assay indicated the involvement of HIF-1 $\alpha$ in the proliferation, apoptosis and invasion of NCI-H157 cells. To investigate the possible mechanisms, the expression levels of associated proteins were determined using western blotting. There were no evident differences observed in the levels of detected proteins between the control and MOCK groups (Fig 4). The expression levels of caspases 3 and 9 were significantly increased in the HIF-1 $\alpha$ siRNA, DDP, MOCK+DDP and HIF- $1 \alpha$ siRNA+DDP groups $(\mathrm{P}<0.01)$, whereas the expression levels of Bcl-2, VEGF, p-PI3K and p-AKT were decreased. Additionally, the effect of HIF-1 $\alpha$ 
A

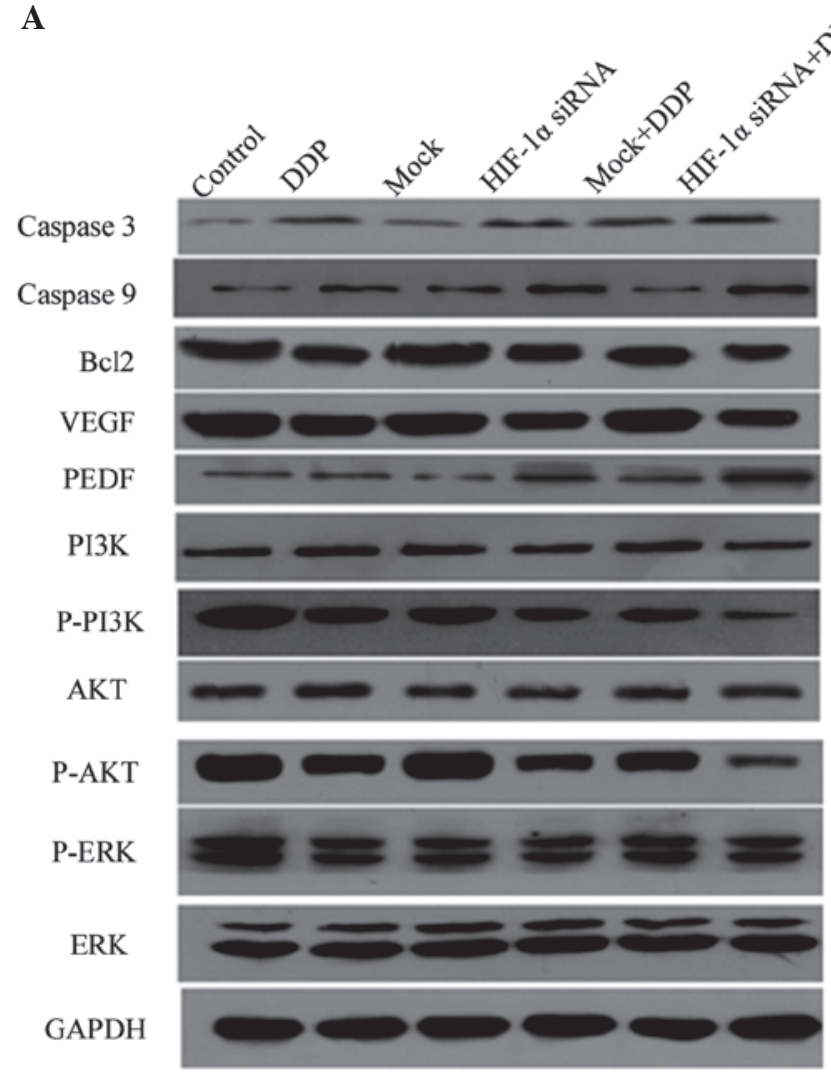

B
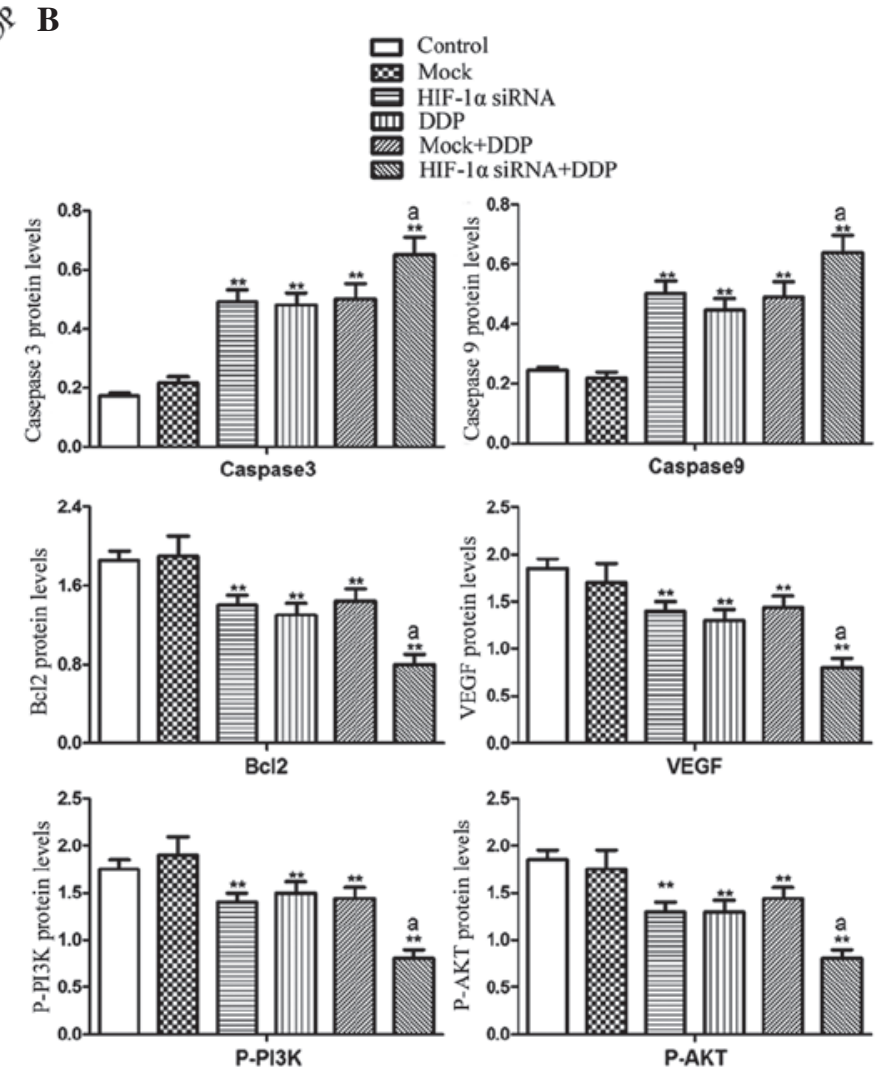

Figure 4. (A) The expression of caspase 3, caspase 9, Bcl-2, VEGF, p-PI3K and p-AKT was detected using western blotting. (B) Quantification of the western blotting membrane signal intensity was performed, and the statistical results of the 3 experiments were presented. The data are expressed as the mean \pm standard deviation $(\mathrm{n}=6) .{ }^{*} \mathrm{P}<0.05,{ }^{* *} \mathrm{P}<0.01$ vs. control. ${ }^{a} \mathrm{P}<0.01$ vs. HIF-1 $\alpha$ siRNA, DDP and MOCK+DDP. Bcl-2, B-cell lymphoma-2; VEGF, vascular endothelial growth factor; PEDF, pigment epithelium-derived factor; PI3K, phosphoinositide 3-kinase; P-PI3K, phosphorylated-PI3K; AKT, protein kinase B; P-AKT, phosphorylated-AKT; ERK, extracellular signal-regulated kinase; P-ERK, phosphorylated-ERK; HIF-1 $\alpha$, hypoxia-inducing factor-1 $\alpha$; siRNA, small interfering RNA; DDP, diamminedichloroplatinum; GAPDH, glyceraldehyde 3-phosphate dehydrogenase.

knockdown on the expression of these proteins was strengthened by DDP treatment.

\section{Discussion}

HIF-1 $\alpha$ knockdown in NCI-H157 cells may inhibit cell proliferation and promote cell apoptosis. Previously, an increase in HIF-1 $\alpha$ expression was indicated to be associated with the progression of gastric cancer (28). Wang et al indicated an association between the breast cancer diffused optical tomography-synthesis diagnostic index and the expression of HIF-1 $\alpha$ (29). Zhou et al indicated that HIF-1 $\alpha$ may promote breast cancer growth (30). Similar to previous studies, the results of the CCK-8 assay in the present study indicated that HIF-1 $\alpha$ knockdown may inhibit NCI-H157 cell proliferation (Fig. 1), which was similar to the effect of the anticancer drug DDP.

Hepatic cholesterol has been previously reported to activate HIF-1 $\alpha$, which may in turn damage the liver cells (31). Jo et al indicated that glucosamine hydrochloride may be used to treat oral tumors that demonstrate a high expression of HIF-1 $\alpha$, through reducing HIF-1 $\alpha$ expression (32). Similar to the study by Jo et al (32), the Annexin V/PI staining data from the present study indicates that HIF-1 $\alpha$ knockdown may promote the apoptosis of NCI-H157 cells (Fig. 2), which was the same effect that was caused by DDP. Additionally, the effects of HIF-1 $\alpha$ knockdown on cell proliferation and apoptosis were strengthened by DDP, which indicated that HIF-1 $\alpha$ siRNA may be combined with DPP for tumor therapy.

HIF-1 $\alpha$ knockdown significantly reduced the invasive ability of NCI-H157 cells. It has been previously reported that HIF-1 $\alpha$ overexpression may be a useful independent prognostic biomarker in gastric cancer (33). Hypoxia is considered to be an important stimulus for tumor angiogenesis, as hypoxia may induce HIF-1 $\alpha$ overexpression and therefore activate platelet-derived growth factor (PDGF) (34). Preventing the microenvironmental adaptations of tumors by reducing the expression of HIF-1 $\alpha$ may be a good method to inhibit craniopharyngioma (35). However, the role of HIF-1 $\alpha$ on the cell invasion of NSCLC has not yet been studied. In the present study, the invasion ability of NCI-H157 was significantly decreased by HIF-1 $\alpha$ knockdown (Fig. 3). Notably, HIF-1 $\alpha$ siRNA and DDP demonstrate combined effects. Therefore HIF-1 $\alpha$ siRNA may be combined with anti-tumor drugs for tumor treatment.

There are certain signaling pathways that are affected by HIF-1 $\alpha$ knockdown. Mitochondria-mediated apoptosis is regarded as the major apoptotic pathway (36), and caspases 3 and 9 may be used as markers of cell apoptosis. Bcl-2 is an anti-apoptotic protein (37). As revealed in Fig. 4, HIF-1 $\alpha$ knockdown significantly increased the expression of caspases 3 and 9, but notably decreased Bcl-2 expression. The 
present data indicated that HIF-1 $\alpha$ knockdown may induce mitochondria-mediated apoptosis.

The PI3K/Akt and Raf/MEK/ERK signaling pathways are important in the process of tumor development (38). In a previous study, the PI3K/AKT pathway and the transcription of HIF-1 $\alpha$ were activated in a cellular model of oral-esophageal carcinogenesis (39). Numerous studies have reported that HIF-1 $\alpha$ expression may lead to organ damage through the MEK/ERK signaling pathway (40-42). Exposure of the neonatal rat brain to hypoxia-ischemia was demonstrated to cause a neonatal brain injury due to the increase of HIF-1 $\alpha$ protein levels and the activation of ERK and AKT (43). In this study, HIF-1 $\alpha$ knockdown significantly decreased the phosphorylation of PI3K and Akt.

Angiogenesis is required for the growth and metastasis of invasive tumors. VEGF is reported to induce endothelial cell proliferation and promote cell migration, and is therefore important in angiogenesis $(34,44)$. PEDF is considered to be an effective inhibitor of angiogenesis by reducing the expression of VEGF (45). In the present study, HIF-1 $\alpha$ knockdown was demonstrated to downregulate VEGF and upregulate PEDF, which indicated that there were inhibitory effects of HIF-1 $\alpha$ knockdown on the VEGF/PEDF pathway.

In addition, the effects of HIF-1 $\alpha$ siRNA on the aforementioned signaling pathways may be strengthened by DDP, which provided additional confirmation in the present study that HIF-1 $\alpha$ siRNA may be combined with DDP for tumor treatment.

In the present study, the knockdown of HIF-1 $\alpha$ was suggested to inhibit the cell proliferation and invasion ability of NCI-H157 cells, which may be associated with the regulation of the PI3K/AKT, Raf/MEK/ERK and VEGF/PEDF pathways. The knockdown of HIF-1 $\alpha$ may also increase mitochondria-mediated cell apoptosis. Furthermore, HIF-1 $\alpha$ siRNA may inhibit tumor growth more effectively when treated with DDP simultaneously.

The present study provides an experimental basis for additional studies that investigate the role of HIF-1 $\alpha$ in tumor progression, although the detailed mechanisms remain to be explored. The present study expands the current understanding of tumor growth and provides an important combined approach for the treatment of tumors.

\section{Acknowledgements}

The present study was supported by the Science Fund of Shanghai Chest Hospital (grant no., YZ14-09).

\section{References}

1. Fenton-Ambrose L and Kazerooni EA: Preventative care: Lung-cancer screens now worth the cost. Nature 514: 35, 2014.

2. Ellis P: Minimally invasive thoracic surgery for early stage non-small cell lung cancer. BMJ 349: g5849, 2014.

3. Lococo F, Cesario A, Leuzzi G and Apolone G: Second primary on-small-cell lung cancer: Implications of the new adenocarcinoma classification in the challenging decision of the best surgical strategy. Eur J Cardiothorac Surg 45: 1115-1116, 2014.

4. Farías RO, Bortolussi S, Menéndez PR and González SJ: Exploring Boron Neutron Capture Therapy for non-small cell lung cancer. Phys Med 30: 888-897, 2014.

5. Zhang Y, Ma M and Han B: GOLPH3 high expression predicts poor prognosis in patients with resected non-small cell lung cancer: An immunohistochemical analysis. Tumour Biol 35: 10833-10839, 2014.
6. Zhang J, Xu L, Yang Z, Lu H, Hu D, Li W, Zhang Z, Liu B and Ma S: MicroRNA-10b indicates a poor prognosis of non-small cell lung cancer and targets E-cadherin. Clin Transl Oncol 17: 209-214, 2015.

7. Zhang L, Qian J, Qiang Y, Huang H, Wang C, Li D and Xu B: Down-regulation of miR-4500 promoted non-small cell lung cancer growth. Cell Physiol Biochem 34: 1166-1174, 2014.

8. Zeuner A, Francescangeli F, Contavalli P, Zapparelli G, Apuzzo T, Eramo A, Baiocchi M, De Angelis ML, Biffoni M, Sette G, et al: Elimination of quiescent/slow-proliferating cancer stem cells by Bcl-XL inhibition in non-small cell lung cancer. Cell Death Differ 21: 1877-1888, 2014.

9. Zhang C, Lan T, Hou J, Li J, Fang R, Yang Z, Zhang M, Liu J and Liu B: NOX4 promotes non-small cell lung cancer cell proliferation and metastasis through positive feedback regulation of PI3K/Akt signaling. Oncotarget 5: 4392-4405, 2014.

10. Wu S, Cheng Z, Yu L, Song W and Tao Y: Expression of CD82/KAI1 and HIF-1 $\alpha$ in non-small cell lung cancer and their relationship to vasculogenic mimicry. Zhongguo Fei Ai Za Zhi 14: 918-925, 2011 (In Chinese).

11. Wang Q, Hu DF, Rui Y, Jiang AB, Liu ZL and Huang LN: Prognosis value of HIF-1 $\alpha$ expression in patients with non-small cell lung cancer. Gene 541: 69-74, 2014.

12. Li Y, Qiu X, Zhang S, Zhang Q and Wang E: Hypoxia induced CCR7 expression via HIF-1 $\alpha$ and HIF- $2 \alpha$ correlates with migration and invasion in lung cancer cells. Cancer Biol Ther 8: 322-330, 2009.

13. Lv Y, and Zhang P: Advances of HIF-1 $\alpha$ and its role in lung cancer. Zhongguo Fei Ai Za Zhi 12: 147-151, 2009 (In Chinese).

14. Jang BC: The fruit juice of Morinda citrifolia (noni) downregulates HIF-1 $\alpha$ protein expression through inhibition of $\mathrm{PKB}$, ERK-1/2, JNK-1 and S6 in manganese-stimulated A549 human lung cancer cells. Int J Mol Med 29: 499-504, 2012.

15. Liang J, Qian Y, Xu D, Yin Q and Pan HJ: Serum tumor markers, hypoxia-inducible factor- $1 \alpha$ HIF-1 $\alpha$ and vascular endothelial growth factor, in patients with non- small cell lung cancer before and after intervention. Asian Pac J Cancer Prev 14: 3851-3854, 2013.

16. Wang Q, Li LH, Gao GD, Wang G, Qu L, Li JG and Wang CM: HIF-1 $\alpha$ up-regulates NDRG1 expression through binding to NDRG1 promoter, leading to proliferation of lung cancer A549 cells. Mol Biol Rep 40: 3723-3729, 2013.

17. Li L, Hu M, Yu JM, Yang GR, Guo HB and Gao Y: Correlations of 99 Tc m-HL91 SPECT hypoxia imaging with HIF-1 $\alpha$ and VEGF expression in non-small cell lung cancer. Zhonghua Zhong Liu Za Zhi31: 669-673, 2009 (In Chinese).

18. Choi YJ, Rho JK, Lee SJ, Jang WS, Lee SS, Kim CH and Lee JC: HIF-1 $\alpha$ modulation by topoisomerase inhibitors in non-small cell lung cancer cell lines. J Cancer Res Clin Oncol 135: 1047-1053, 2009.

19. Zuo S, Ji Y, Wang J and Guo J: Expression and clinical implication of HIF- $1 \alpha$ and VEGF-C in non-small cell lung cancer. J Huazhong Univ Sci Technolog Med Sci 28: 674-676, 2008.

20. Li Y, Zhang Q, Jiang L, Qiu X, Wang E: Upregulation of the chemokine receptor CCR7 expression by HIF-1 $\alpha$ and HIF-2 $\alpha$ in non-small cell lung cancer. Zhongguo Fei Ai Za Zhi 11: 724-728, 2008 (In Chinese)

21. Ai B, Pan T, Zheng Z and Chen T: The relationship of expression of GLUT1, HIF-1 $\alpha$ and the uptake of FDG in non-small cell lung cancer. Zhongguo Fei Ai Za Zhi 10: 508-512, 2007 (In Chinese)

22. Song X, Liu X, Chi W, Liu Y, Wei L, Wang X and Yu J: Hypoxia-induced resistance to cisplatin and doxorubicin in non-small cell lung cancer is inhibited by silencing of HIF-1a gene. Cancer Chemother Pharmacol 58: 776-784, 2006.

23. Zhu C, Wang X, Zheng H, Liu T, Li Y, Sun C, Wang A, Zhao F: Expressions of EphB4 and HIF-1 $\alpha$ in human lung cancer and their significances. Zhongguo Fei Ai Za Zhi 8: 99-102, 2005.

24. Chang H, Shyu KG, Lee CC, Tsai SC, Wang BW, Hsien Lee Y and Lin S: GL331 inhibits HIF-1 $\alpha$ expression in a lung cancer model. Biochem Biophys Res Commun 302: 95-100, 2003.

25. Jacoby JJ, Erez B, Korshunova MV, Williams RR, Furutani K, Takahashi O, Kirkpatrick L, Lippman SM, Powis G, O'Reilly MS, et al: Treatment with HIF-1 $\alpha$ antagonist PX-478 inhibits progression and spread of orthotopic human small cell lung cancer and lung adenocarcinoma in mice. J Thorac Oncol 5: 940-949, 2010.

26. Wan J, Ma J, Mei J and Shan G: The effects of HIF-1 $\alpha$ on gene expression profiles of NCI-H446 human small cell lung cancer cells. J Exp Clin Cancer Res 28: 150, 2009. 
27. Peng Z, Shan C and Wang H: Expression of VHL and HIF-10 and its clinical significance in the lung cancer tissue. Zhong Nan Da Xue Xue Bao Yi Xue Ban 34: 331-334, 2009 (In Chinese).

28. Naruke A, Azuma M, Takeuchi A, Ishido K, Katada C, Sasaki T, Higuchi K, Tanabe S, Saegusa M and Koizumi W: Comparison of site-specific gene expression levels in primary tumors and synchronous lymph node metastases in advanced gastric cancer. Gastric Cancer 18: 262-270, 2015.

29. Wang HL and Zhang ZL: Analysis of the relationship between ultrasound of breast cancer DOT-SDI and the expression of MVD, VEGF and HIF-1 $\alpha$. Cell Biochem Biophys 70: 205-208, 2014.

30. Zhou Z, Liu F, Zhang ZS, Shu F, Zheng Y, Fu L and Li LY: Human rhomboid family-1 suppresses oxygen-independent degradation of hypoxia-inducible factor- $1 \alpha$ in breast cancer. Cancer Res 74: 2719-2730, 2014.

31. Anavi S, Hahn-Obercyger M, Madar Z and Tirosh O: Mechanism for HIF-1 activation by cholesterol under normoxia: A redox signaling pathway for liver damage. Free Radic Biol Med 71: 61-69, 2014.

32. Jo JR, Park YK and Jang BC: Short-term treatment with glucosamine hydrochloride specifically downregulates hypoxia-inducible factor- $1 \alpha$ at the protein level in YD-8 human tongue cancer cells. Int J Oncol 44: 1699-1706, 2014.

33. Chen L, Shi Y, Yuan J, Han Y, Qin R, Wu Q, Jia B, Wei B, Wei L, Dai G, et al: HIF-1 $\alpha$ overexpression correlates with poor overal survival and disease-free survival in gastric cancer patients post-gastrectomy. PLoS One 9: e90678, 2014.

34. Clara CA, Marie SK, de Almeida JR, Wakamatsu A, Oba-Shinjo SM, Uno M, Neville $M$ and Rosemberg S: Angiogenesis and expression of PDGF-C, VEGF, CD105 and HIF-1 $\alpha$ in human glioblastoma. Neuropathology 34: 343-352, 2014.

35. Liu H, Liu Z, Li J Li Q, You C and Xu J: Relative quantitative expression of hypoxia-inducible factor $1 \alpha$ messenger ribonucleic acid in recurrent craniopharyngiomas. Neurol India 62: 53-56, 2014.

36. Green DR: Apoptotic pathways: Paper wraps stone blunts scissors. Cell 102: 1-4, 2000.

37. Reed JC: Double identity for proteins of the Bcl-2 family. Nature 387: 773-776, 1997.
38. De Luca A, Maiello MR, D'Alessio A, Pergameno $M$ and Normanno N: The RAS/RAF/MEK/ERK and the PI3K/AKT signalling pathways: Role in cancer pathogenesis and implications for therapeutic approaches. Expert Opin Ther Targets 16 (Suppl 2): S17-S27, 2012.

39. Heeg S, Hirt N, Queisser A, Schmieg H, Thaler M, Kunert H, Quante M, Goessel G, von Werder A, Harder J, et al: EGFR overexpression induces activation of telomerase via PI3K/AKT-mediated phosphorylation and transcriptional regulation through Hif 1- $\alpha$ in a cellular model of oral-esophageal carcinogenesis. Cancer Sci 102: 351-360, 2011.

40. Richard DE, Berra E, Gothié E, Roux D and Pouysségur J: p42/p44 mitogen-activated protein kinases phosphorylate hypoxia-inducible factor 1alpha (HIF-1alpha) and enhance the transcriptional activity of HIF-1. J Biol Chem 274: 32631-32637, 1999.

41. Minet E, Arnould T, Michel G, Roland I, Mottet D, Raes M, Remacle J and Michiels C: ERK activation upon hypoxia: Involvement in HIF-1 activation. FEBS Lett 468: 53-58, 2000.

42. Hur E, Chang KY, Lee E, Lee SK and Park H: Mitogen-activated protein kinase kinase inhibitor PD98059 blocks the trans-activation but not the stabilization or DNA binding ability of hypoxia-inducible factor- $1 \alpha$. Mol Pharmacol 59: 1216-1224, 2001.

43. van den Tweel ER, Kavelaars A, Lombardi MS, Nijboer CH, Groenendaal F, van Bel F and Heijnen CJ: Bilateral molecular changes in a neonatal rat model of unilateral hypoxic-ischemic brain damage. Pediatr Res 59: 434-439, 2006.

44. Zhang E, Feng X, Liu F, Zhang P, Liang J and Tang X: Roles of PI3K/Akt and c-Jun signaling pathways in human papillomavirus type 16 oncoprotein-induced HIF-1 $\alpha$, VEGF, and IL-8 expression and in vitro angiogenesis in non-small cell lung cancer cells. PLoS One 9: e103440, 2014.

45. Yamagishi S, Matsui T, Nakamura K, Yoshida T, Shimizu K, Takegami Y, Shimizu T, Inoue $\mathrm{H}$ and Imaizumi $\mathrm{T}$, et al: Pigment-epithelium-derived factor (PEDF) inhibits angiotensin-II-induced vascular endothelial growth factor (VEGF) expression in MOLT-3 T cells through anti-oxidative properties. Microvasc Res 71: 222-226, 2006. 